\title{
Separated by a common technology? Factors affecting ICT-related activity in home and school
}

\author{
David Benzie \\ College of St Mark \& St John, Derrifird Road, Plymouth PL6 8BH, UK; \\ David_Benzie@compuserve.com
}

\begin{abstract}
There has been a steady growth in the number of computers in both home and school over the last decade and it is now clear that there is the potential for activities in those settings to be linked through a common technology.

This paper explores the relationship between computer-based activities in home and school by considering each of those settings as a distinct, but related, community of practice. The exploration of the relationship is based on Benzie's (2000) research that highlights the significance of power, motivation and legitimacy as forces which affect, in Lave and Wenger's (1991) terms, peripheral participation in a community of practice. The paper suggests that this perspective can be used to help shape worthwhile Information and Communication Technology (ICT)-related activities that link home and school.
\end{abstract}

Key words: social contexts, conditions for learning, sites of learning, organising for learning, roles and relationships

\section{INTRODUCTION}

There has been steady growth in the number of computers in homes and schools over the last decade. In the UK, by 1999 about 75 percent of children aged 7-11 claimed to have a computer at home (BECTa 2001a) and in primary schools the average computer-to-pupil ratio stood at 11:8 (DfES 2001). Given that a growing proportion of computers in both settings have an Internet connection and are PC compatibles running Microsoft Windows, it is clear that there is considerable scope for activities in those settings to be linked with the computer acting either as a platform to support similar

The original version of this chapter was revised: The copyright line was incorrect. This has been corrected. The Erratum to this chapter is available at DOI: 10.1007/978-0-387-35668-6_17 
activities in both contexts or as a mediator for communication between the two. BECTa's (2001b) report on the use of ICT to support home-school links, based on case studies in eight schools, highlights the early stage of developments in those institutions and also draws attention to the nature of their activities. As has been the case with other technology-related innovations in education, early concerns are with the technology itself (in this case, network infrastructures and web servers) and with using the technology to replicate and extend, as opposed to radically transform, current practice.

The pattern is hardly surprising but projects that seek to build worthwhile links between home and school need to take account of the social complexities in the two settings and the differences between them, that are richly illustrated in reports by Downes (1999), Facer, et al. (2001), McNamara, et al. (2000), Sanger, et al. (1997) and (2001a). Benzie's (2000) study of the development of student IT capability, written from the perspective of Lave and Wenger's (1991) and Wenger's (1998) theories concerning Communities of Practice, addresses a setting with features that resonate with the authors' reports despite its focus on adult and emerging adult learners. Two questions follow from Benzie's (2000) study. Firstly, "What are the messages concerning the relationship between ICT-related activities in one context and those in another?" Secondly, "What messages are there for those who seek to create ICT supported home-school links?" The questions are addressed in this paper.

\section{THE DEVELOPMENT OF IT CAPABILITY: AN EXAMPLE OF ACTIVITY IN MULTIPLE CONTEXTS}

Benzie (2000) studied the development of students' IT capability over a period of two and a half years whilst they completed undergraduate degrees. About half of the students were trainee teachers. In almost all cases the students developed their IT capability in multiple contexts, home, college and school were the most significant; but other contexts, such as church and the work place, also featured. The exploration of activity in those settings, using Wenger's (1998) perspectives on Communities of Practice, led to a number of significant conclusions.

The first conclusion was that different settings could be seen as separate but connected Communities of Practice. Individuals were almost invariably members of multiple communities (e.g., trainee teachers were part of a college community and, whilst on teaching practice, a school community), and they played a key role in linking practice. They "brokered", to use 
Wenger's (1998) terminology, between different communities. However in spite of patterns of multiple membership, it was clear that conceptions of ICT capability varied between communities. In other words, ICT capability is a situated concept that only acquires meaning when referenced to a context.

The second conclusion concerned the identity of a learner. It was clear that the students in the study were active agents whose actions shaped and were shaped by the communities to which they belonged. In other words, there is a mutually constitutive relationship between the two. The relationship was neatly illustrated by a student who introduced new ideas into one of his teaching practice schools whilst his conception of good classroom practice shifted as he moved from one school to another.

A third conclusion concerned the manner in which individual engagement in a community of practice is shaped. Benzie (2000) concluded that engagement in community activity is shaped by the resulting force from three web-like structures, "Power", "Motivation" and "Legitimacy" as shown in Figure 1.

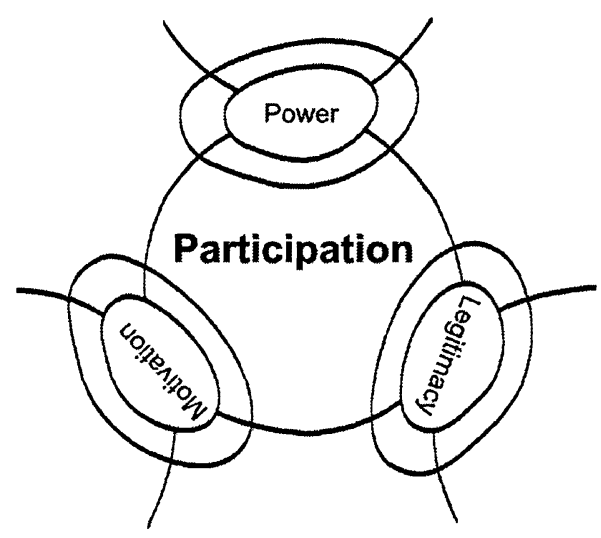

Figure 1. Patterns of participation and the webs of power, motivation and legitimacy. (Benzie 2000)

In order to engage in community activity an individual has to negotiate a set of power relationships with other members of the community who control access to the resources that are required. An individual's ability to conduct the negotiations can be affected by circumstances in other communities to which they belong. In the case of students there is, for example, an advantage that comes from having the funds to buy books and equipment that they perceive they need for enjoyment or professional development. 
The motivational forces that affect participation in a community are complex. Lave and Wenger (1991) distinguish between "Use value" (e.g., "I can make direct use of the product of participation to enable me to achieve Y") and "Exchange value" (e.g., "If I gain qualification X, I can exchange it for a position in community Z"). The distinction draws attention to the way in which engagement in one community influences motivation to engage in another. Students in Benzie's (2000) study navigated interconnecting webs of motivating forces, linked to their membership of multiple communities, as they approached new activities.

The third web concerns the way in which specific activities are deemed legitimate. Communities draw distinctions between what is, and is not, a legitimate activity. A significant part of the story of becoming a member of a specific community is learning to appropriate and deploy the rationales which legitimate and promote some forms of activity in preference to others. However the legitimising rationales that individuals create for a specific activity are inevitably drawn, in part, from the other communities to which they belong. This can be very significant. For example, some students are, or have been, members of communities where play is not seen as a legitimate adult activity; rather, play is equated with time wasting. This can have disastrous consequences when the student seeks to participate in a community, such as many ICT-related communities, where "playful" activities are particularly effective.

Participation in one community can influence participation in another. The significance of this is illustrated by Wenger's (1998) suggestion that the role of education is to place "students on an outbound trajectory toward a broad field of possible identities." Peripheral participation leading to an outbound trajectory with multiple connections and outcomes can be seen in Figure 2.

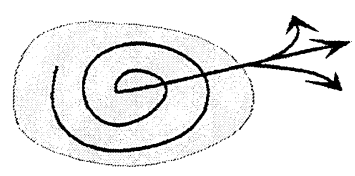

Figure 2. Peripheral participation in an academic community of practice leading to a broad field of possible identities. (Benzie 2000)

The figure illustrates the multiple trajectories and also suggests a dynamic in which a successful educational community promotes "peripheral participation", a positive term from Lave and Wenger's lexicon, in the activities that it legitimates. The quality of peripheral participation in an educational community may be judged by the effectiveness with which 
students are prepared for roles in other communities. Special attention should be paid to the role that an educational community has in enabling students to develop identities that are characterised by their negotiability in other contexts.

Benzie (2000) suggests that there are a number of characteristics of a higher education community that enable its learners to develop negotiable identities.

A successful community:

- continuously renegotiates the meaning and significance of the objects and conceptual frameworks that are associated with its activities;

- organises the peripheral participation of students in ways that expose the canonical meaning and significance of community objects and frameworks to them whilst also enabling them to negotiate specific meanings, linking those objects and frameworks to activity in other communities of which they are a member;

- ensures that student participation is periodically scrutinised by lecturers the purpose of scrutiny is to maintain peripheral as opposed to marginal patterns of participation;

- encourages students to play emerging master roles in their interactions with peers; peripheral participation is associated with moves towards symmetrical relationships;

- places a high value on activities associated with exploration and reflection, both should occur within the frame of contemporary community activity and at the boundary with other communities;

- regards the giving and receiving of help as particularly significant activities;

- provides, maintains and grants access to the physical resources that are required to facilitate participation.

Home and school can also be seen as communities of practice so the message from the research for those who seek to initiate ICT supported home-school links will now be considered.

\section{ICT AND HOME-SCHOOL LINKS: SOME SUGGESTIONS}

When the development of identity is fundamentally linked to educational aims, as illustrated in Figure 2, activity may be tested by the question, "Is the activity structured in a way that allows children to develop identities that are negotiable in a broad range of contexts beyond school?" The word "structure" is a heavily loaded one for it carries the baggage of the socio- 
cultural context in which activity takes place. Focusing discussion about ICT and home-school links around the concepts of power, motivation and legitimacy helps to keep these issues in the foreground.

\subsection{Power}

It is all too easy to reduce issues of power to one of domestic finance. Any attempt to use ICT to support home-school links will have to consider the availability of computers, software and network services in the home but this should not be the only consideration.

Research by Downes (1999) suggests that when computers are available in a home children have little difficulty in negotiating access in order to enable them to complete school-related tasks as those tasks are generally given a high priority. What is significant is who exercises the power to dictate the nature of the school-related activities. If children are not allowed to play a part in shaping them they will simply maintain and reinforce the asymmetrical power relationship that generally exists between adult and child.

There is a second sting. If parents and teachers retain control of all aspects of activity that link home and school they will surely use the technology to increase their surveillance of children. Home-school e-mails will focus on what the child, as a third party, is (or is not) doing as he or she trudges towards a goal that $\mathrm{s} / \mathrm{he}$ has played no part in choosing. The lure of automated registration systems that allow parents to check their child's attendance at each and every lesson, simply by logging on to the school web site, will be irresistible even though the reality is that only a small proportion of children really need their attendance to be closely monitored. Such a use of technology to subjugate children may have outcomes that are the very opposite of the ones that are desired.

Children's activities do need to be scrutinised by adults but the purpose of scrutiny is not to dominate and subjugate. Rather, it is to uncover misunderstandings and misconceptions in ways that help barriers to progress to be removed. For teachers and parents, the process of scrutiny should help to illuminate differences between home and school conceptions of activity in a way that can then lead to renegotiation and an increased degree of alignment between the two.

The tendency to subjugate can be countered by allowing children to have some say in the determination of activities that underpin home-school links. There would be at least two significant benefits from this. Firstly, children would be highly likely to base some of their suggestions on their experiences in communities beyond home and school, so activities associated with homeschool would play a positive role in helping them to negotiate positions in 
those communities. The second benefit is that allowing children to play a part in shaping activity creates a channel through which parents and teachers can become more aware of the nature of activities that children choose to engage in. Teachers may not see this as a benefit because of the challenge that it presents to traditional school-directed activity but the alternative is a growing gulf between activity in home and school.

\subsection{Motivation}

Effective home-school links will only be created and maintained if teachers, parents and children all have a stake in their success. McNamara, et al. (2000) say that knowing that their child is "doing OK" is the central concern for many parents. It is clear that computer technology can provide a channel for relatively straightforward communication on the subject. Many parents also want help to enable them to support their children with homework and they frequently miss the paper-based information that is erratically conveyed from home to school in children's bags. There are some obvious ICT-related solutions to those issues, though the solutions are based on the assumption that technology is available in the home and that the culture in the home is supportive of the school and its aims.

Superficially, children are motivated to engage in an activity by its immediate, as opposed to its long term, value. For this reason, generalised appeals to "develop life skills", for example, are likely to be futile. Adults generally convert long-term educational objectives for children into a series of short-term ones such as grade achievement. Attempts to motivate children to engage in activity (e.g., home use of online revision materials) by creating a link with the achievement of better grades at school will be heavily mediated by the home perspective on achievement at school.

An alternative approach is for schools to seek to stimulate activities in the home that have an immediate value, possibly in terms of enhanced status, to the child either in the context of home or in a context beyond home and school. Encouraging children to look for ICT tractable problems in the home, or in other social groups to which they belong, and then to devise and implement solutions to those problems is just one way in which this might be done. This gives the added virtue of creating a channel through which homes can influence school.

Attempts to motivate teachers are always going to face difficulties in contexts where they are assessed according to their ability to guide children through national tests that are structured in ways that promote a view of legitimate activity that differs widely from the view of legitimacy that exits in many homes. The flow of ideas from home to school is likely to complicate the traditional patterns of a teacher's day-to-day practices as the 
messages associated with those ideas will not fit in comfortably with other pressures. Current structures in education encourage teachers to see ICT mediated home-school links as largely uni-directional, and as an agent through which power and control are exerted. Such a perspective will only be countered if teachers can be motivated to hear, and act on, the messages that flow back to school. Constructing joint enterprises between home and school, in which both have a stake, is one way in which this could happen.

\subsection{Legitimacy}

A key aspect of the difference between home and school concerns the conception of legitimate uses for technology. Parents in many homes willingly legitimate school-related activity but there are also some significant cultural barriers between school and many homes. Children, for example, inhabit an electronic world where the wholesale swapping and sharing of electronic resources (especially music and, increasingly, video) is seen as entirely legitimate. This is at odds with notions of legitimacy that schools are required to promote.

The legitimacy, or otherwise, of ways of working is also an issue. Exploration and "fiddling around" are, for example, effective learning strategies that many young children use quite naturally. However they are not always legitimated at school or in some homes. In the long run social pressures lead many children to de-legitimise them. Schools seeking to build effective ICT-mediated home-school links need to consider the legitimacy that is accorded in each context to the ways of working that are implicit in any proposed activity.

The availability of help in each context for activity is critical and the way in which it is provided reflects a perspective on legitimate activity. If, for example, completion of a task by any available means is seen as legitimate, it is likely that children will seek help in ways that actually hinder their longterm progress, as when children develop a private economy in which they complete homework for each other. There are some delicate issues here because children do need to learn to play emerging master roles with their peers and one way they can do this is to become a source of help for each other.

\section{CONCLUDING REMARKS}

Research by Downes (2000), Facer, et al. (2001) and Sanger, et al. (1997) highlights the dislocation that exists between the home and school ICTrelated tasks that many children engage in. There are, however, many good 
reasons for wanting to build more effective links between home and school, and ICT has created new ways in which this can happen.

Effective links depend on far more than technology. Building links will present a challenge to cultures in both home and school as dislocations between the two contexts are grappled with. A vocabulary to support the discussion, and a perspective on the nature of the challenges, can be generated by considering two contexts as communities of practice. When children are seen as active agents who participate in the activities of multiple communities, attention is drawn to the web-like forces of power, motivation and legitimacy with which they engage. They traverse the webs in their own way, but their patterns of engagement in community activity are nonetheless shaped by webs that draw threads from each community to which they belong. School and home are, for most children, but two of the communities in which they are involved. Awareness of the role of power, motivation and legitimacy in home-to-school connections can be used to help design homeschool links that liberate, rather than subjugate, children.

\section{REFERENCES}

BECTa (2001a). ImpaCT2: Emerging Findings from the Evaluation of the Impact of Information and Communication Technologies on Pupil Attainment. London: DfES http://www.becta.org.uk/impact2.

BECTa (2001b). Using ICT to Enhance Home-school links. An Evaluation of Current Practice in England. London: DfES http://www.becta.org.uk/homeschoollinks.

Benzie, D.H. (2000) A longitudinal study of the development of information technology capability by students in an institute of higher education. Unpublished Ph.D. thesis. Exeter: University of Exeter. David Benzie@compuserve.com.

DfES (2001). Survey of Information and Communications Technology in Schools 2001. National Statistics Bulletin Issue No 09/01 October 2001. London: HMSO.

Downes, T. (1999) Playing with computing technologies in the home. Education and Information Technologies 4 1 65-79.

Facer, K., Sutherland, R., Furlong, R. and Furlong, J. (2001) What's the point of using computers? The development of young people's computer expertise in the home. New Media \& Society 32 199-219.

Lave, J. and Wenger, E. (1991) Situated Learning. Legitimate Peripheral Participation. Cambridge: Cambridge University Press.

McNamara, O., Hustler, D., Stronach, I., Rodrigo, M., Beresford, E. and Botcherby, S. (2000) Room to manoeuvre: mobilising the 'active partner' in home-school relations. British Educational Research Journal 264 473-489.

Sanger, J., Willson, J., Davies, B. and Whittaker, R. (1997) Young Children, Videos and Computer Games. Issues for Teachers and Parents. London: Falmer Press.

Wenger, E. (1998) Communities of Practice. Learning, Meaning, and Identity. Cambridge: Cambridge University Press. 


\section{BIOGRAPHY}

David Benzie is the Director of the Centre for Information Technology in Education (CITE) at the College of St Mark \& St John. He teaches a wide range of courses, including those that focus on in-service and pre-service training for teachers. His research is concerned with socio-cultural theories of learning and the contribution that they can make to the design of learning environments. He is a member of IFIP's Working Group 3.5. 